\title{
CHLORIDE SEGREGATION ALONG GRAIN BOUNDARIES IN ICE
}

\author{
By F. Prodi* and C. T. Nagamoto \\ (National Center for Atmospheric Research, $\uparrow$ Boulder, Colorado 80302, U.S.A.)
}

\begin{abstract}
A new technique for precisely detecting chlorides in ice has been developed. It is based on a microchemical contact reaction which takes place when a thin surface layer of ice melts through a membrane filter previously soaked in a concentrated solution of silver nitrate and dried. The silver chloride thus formed is reduced to metallic silver under ultra-violet light. The results on natural hailstones and laboratory doped ice show that foreign molecules are mainly segregated along the grain boundaries rather than being captured in the ice lattice.

The technique, which makes quantitative evaluations possible, appears promising in all experimental studies on natural ice (hailstones and sea ice) and on ice artificially grown in the laboratory (by accretion or by freezing of solutions).

RÉsumÉ. Séparation des chlorures à la surface des grains de glace. On a mis au point une nouvelle technique pour détecter avec précision les chlorures dans la glace. La technique est fondée sur une microréaction chimique de contact qui a lieu lorsqu'une mince pellicule à la superficie de la glace fond à travers une membrane filtrante préalablement chargée d'une solution concentrée de nitrate d'argent et séchée. Le chlorure d'argent qui resulte réagit sous lumière ultraviolette pour former de l'argent métallique. Les résultats sur des grêlons et sur de la glace dopée en chlorures au laboratoire montrent que les molécules étrangères sont en très grande majorité repoussées le long de la surface des grains plutôt que capturées dans l'intérieur du réseau cristallin dans la glace.

La technique qui permet des évaluations quantitatives apparaît prometteuse dans toutes les études expérimentales sur la glace naturelle (grêlons et glace de mer) et sur la glace artificiellement formée en laboratoire (par accrétion ou par gel de solutions).

Zusammenfassung. Chloridabsonderung entlang Korngrenzen in Eis. Eine neue Technik zur sicheren Feststellung von Chloriden in Eis wurde entwickelt. Sie beruht auf einer mikrochemischen Kontaktreaktion, die eintritt, wenn eine dünne Oberflächenschicht von Eis durch ein Membranfilter schmilzt, das zuvor in einer konzentrierten Silbernitratlösung getränkt und dann getrocknet wurde. Das resultierende Silberchlorid reagiert auf ultraviolettes Licht mit der Bildung von metallisches Silber. Die Resultate bei Versuchen mit natürlichen Hagelkörnern und mit künstlich verunreinigtem Eis zeigen, dass Fremdmoleküle eher vornehmlich entlang der Korngrenzen abgesondert sind, als dass sie vom Eisgitter umschlossen werden.

Die Technik, die quantitative Auswertungen ermöglicht, erscheint vielversprechend bei allen experimentallen Untersuchungen an Natureis (Hagel und Meereis) und an künstlich im Labor gewachsenem Eis (durch Zuwachs oder durch Gefrieren von Lösungen).
\end{abstract}

\section{INTRODUGTION}

The chemistry of the solidification of water containing foreign material is not as well known as is the thermodynamics involved in the process. The most generally accepted techniques for detecting the distribution of impurities in ice are the chemical analysis of melted sections cut at different distances from the surface, the thermal and chemical etching of the ice surface, and the microchemical analysis of residues after sublimation of ice slices. For a variety of reasons, all of them prove to be unsatisfactory in exactly locating the impurities in connection with grain boundaries, subgrains, dislocations, and air bubbles of the parent ice. Melting techniques are obviously unsatisfactory; in thermal etching Levi and others (1964) observed different features in pure and doped ice during controlled evaporation, but they did not state definite conclusions since their results were affected by the sublimation rate. Furthermore, Itagaki (1967) indicated a mechanism of mass flow along an ice surface, enhancing the existence of a liquid-like layer or a diffusion layer on the surface during sublimation; from this observation it is doubtful whether the thermal etching technique can locate solute segregation in ice. A similar mechanism also affects the results of microchemical analysis performed on residues of contaminated ice after complete sublimation of thin slices. A small scale migration of solute material and agglomeration of particles was

* On leave from the Istituto di Fisica dell'Atmosfera del CNR, Sezione di Bologna, Italy.

$\dagger$ The National Center for Atmospheric Research is sponsored by the National Science Foundation. 
observed by Prodi and others (1970) during sublimation of contaminated ice grown by accretion.

Recently Mizuno and Kuriowa (I970) developed a technique for detecting solute material in ice by autoradiography. Although this technique is successful in demonstrating that solute segregation occurs primarily along grain boundaries, it seems to be applicable only to ice artificially grown with radioactive $\beta$-ray tracers in solution. Furthermore, the blackness of spots in the autoradiographic technique may depend upon the distance between the emulsion and the radioactive solute embedded in the ice.

The purpose of this paper is to describe a simple technique using millipore filters which allows a high sensitivity detection of chlorides in natural and artificial ice in correspondence with internal features, and which provides a quantitative method for evaluation of chlorides.

\section{EXPERIMENTAL TEGHNIQUE}

A white millipore filter $(0.8 \mu \mathrm{m}$ and $0.22 \mu \mathrm{m}$ pore size) was soaked in a concentrated solution of $\mathrm{AgNO}_{3}$ and then almost completely dried in a contamination-free environment. The ice surface to be inspected was previously shaved to a plane with a microtome at a temperature below the eutectic point to avoid transportation of solute material by the microtome blade. The filter was then placed on the ice surface and heated by a warm metal block with an absorbent paper interposed. As soon as the filter was wetted by the first melted layer, it was placed under ultra-violet light until the peculiar brown patterns of AgCl reduced to metallic silver were visible on the filter. When dry, the filter was examined under the microscope.

In examining ice with high $\mathrm{NaCl}$ content, it is not necessary to warm the surface, as liquid inclusions in the solid structure can wet the filter and give reactions at temperatures far below $0^{\circ} \mathrm{C}$. In this technique, by placing the filter and the superimposed ice surface on a cold plate whose temperature is precisely regulated, it is possible to have chloride distribution in ice as a function of temperature.

A modification of the filter technique can be used when investigating particle distribution in hailstones, and may make possible a better interpretation of hailstone growth conditions. A thin ice slice is melted between two filters and subsequently filtered through them onto an absorbent paper backing. The filters are then separated, and each may be treated for other analyses such as for the nucleating ability of particles (following the technique of Langer, unpublished) or for a microchemical analysis to detect iron particles (Vittori and others, I969).

When the ice surface has been examined, it can be shaved off a few micrometers with the microtome; a new analysis may then be performed to detect chlorides at this lower level, thus giving the chloride distribution in the slice thickness.

\section{Results AND Discussion}

\section{A. Chlorides in natural hailstones}

Chloride filter replica experiments were performed on hailstones from different precipitations in the Colorado-Nebraska region. The results on a hailstone collected at Niwot, Colorado, ro June 1969 and another at Chadron, Nebraska, 7 June 1967 are shown in Figures I and 2, respectively.

Figure $\mathrm{I}$ is a crossed polar polarized light photograph of a slice that is close to that analyzed for chlorides, in which the structure of crystals is evidenced, and the zones of the enlargements of the chloride analysis are indicated. A thin layer having been shaved away by the microtome, the correspondence between crystals and chloride pattern is not exact. In Figures ra, $\mathrm{Ib}$, and Ic, enlarged details of the replica on a millipore filter $(0.22 \mu \mathrm{m}$ pore size $)$ are shown. The sensitivity of the filter technique makes chloride detection possible (Fig. 5) in hailstones of low $\mathrm{NaCl}$ content such as those from the precipitation in the Colorado-Nebraska region. 
The first result is confirmation of Mizuno and Kuroiwa's (1970) conclusion that solute molecules are not incorporated within the ice lattice but are mainly segregated along grain boundaries; in fact, a perfect correspondence between chloride patterns and grain boundaries was observed.

By comparing Figure $\mathrm{Ib}$ with Figure $\mathrm{s}$ a or Figure Ic, it can be seen that small crystals produce strong patterns, while larger crystals show faint patterns. This behavior may be
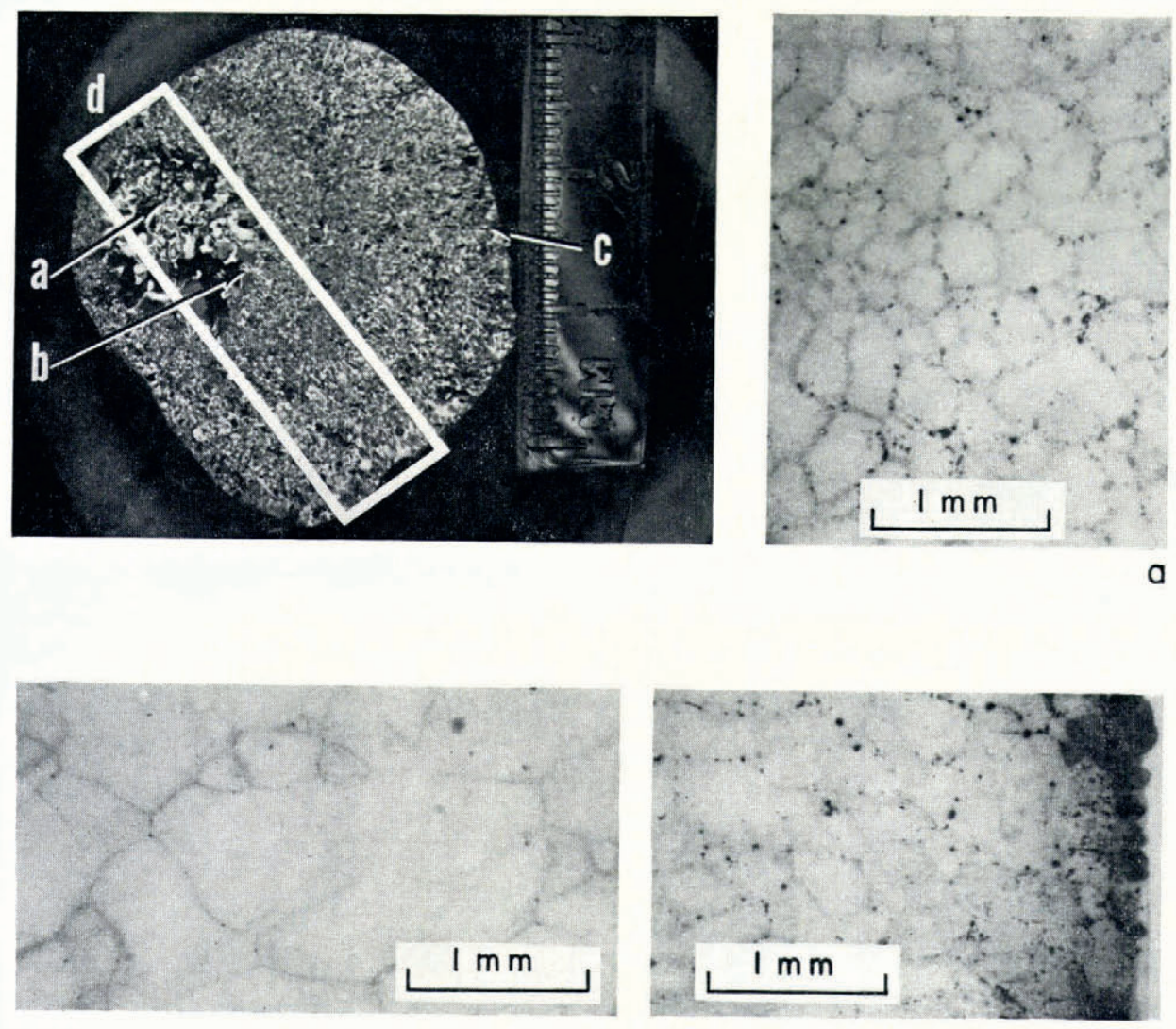

b

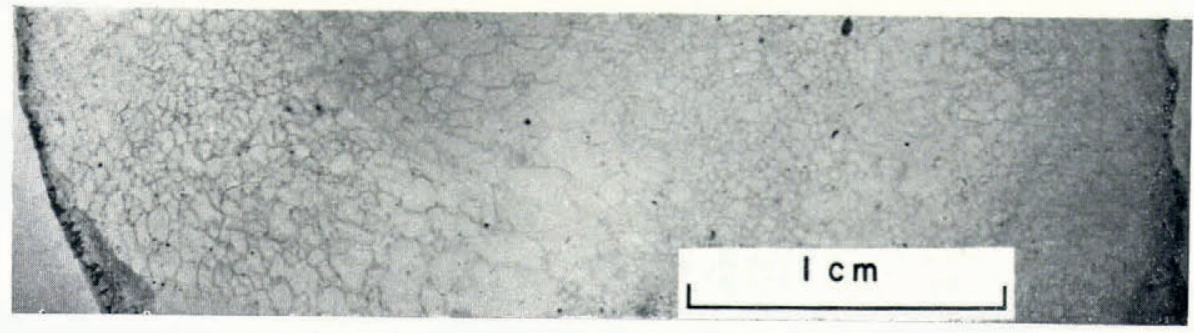

d

Fig. I. Crossed polarized light picture of a hailstone slice (Niwot, Colorado, Io June 1969), with chloride reaction replicas on filter at the area near the corresponding zones shown by the arrows and near the strip marked. 
explained by variations in the rate of crystallization; when the rate is low large crystals are produced and the crystallization front rejects a larger amount of solute. Nevertheless, fluctuations in the chloride content of accreted droplets of a cloud may also affect the chloride distribution, as can be seen from Figures $2 \mathrm{~b}$ and $2 \mathrm{c}$, where enlarged details in a transition region of crystals are shown. In this situation, a sharp decrease is seen in chloride content going from larger radial crystals to smaller ones. This behavior contrasting with that of the
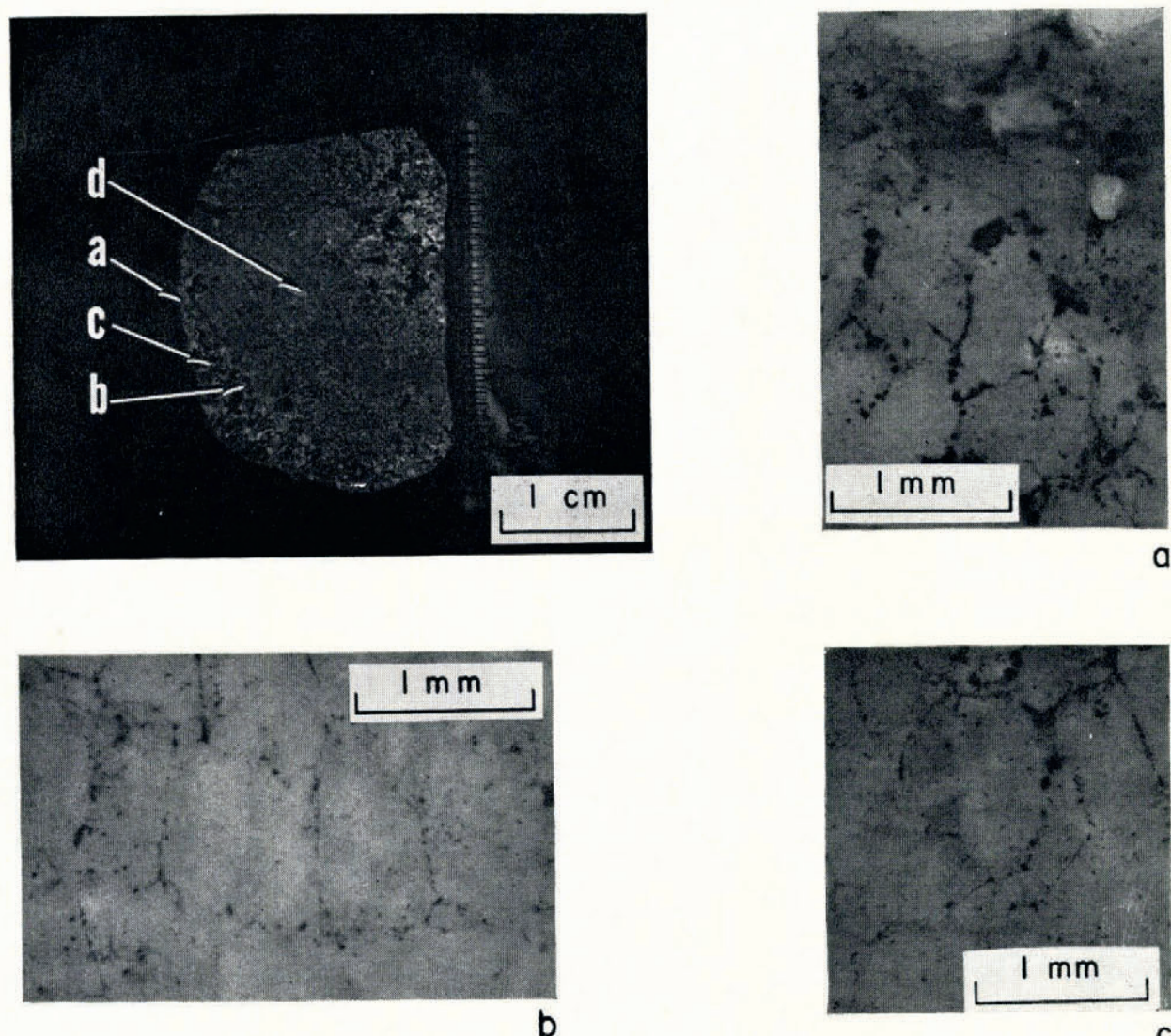

$\mathrm{C}$

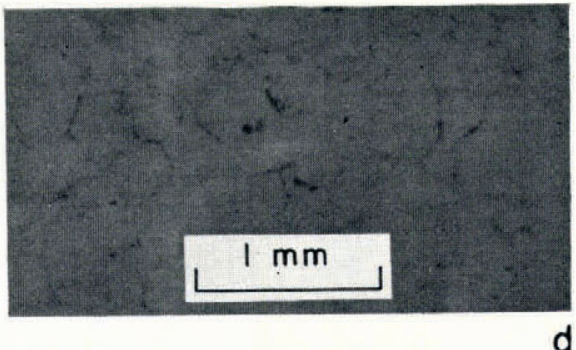

Fig. 2. Crossed polarized light picture of a section of a hailstone slice (Chadron, Nebraska, 7 June, 1967), with chloride reaction replicas on the filter at the area near the corresponding zone shown by the arrows. 
former hailstone may be explained by the inner layer (the small crystals) being completely frozen in a "non-porous" structure, and the outer layer superimposed, no longer permitting the liquid penetration of high chloride content from the outside during final freezing. It should also be noted in this hailstone (Fig. 2a) as well as in all those examined (Fig. re, Fig. 6) that the periphery of the slice was always characterized by a high quantity of chloride from both solute material (reactions along grain boundaries) and undissolved material (reactions corresponding with contaminating particles; see Figure 6). Penetrating channels of reactions due to particles were also frequently observed from the periphery toward the center (Fig. 6).

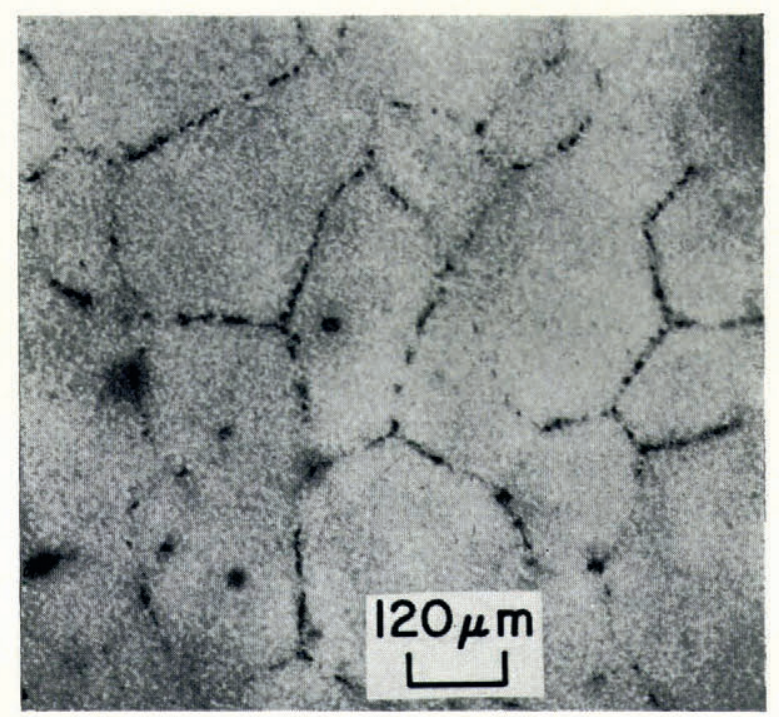

Fig. 3. Chloride reaction patterns of grain boundaries on $0.8 \mu \mathrm{m}$ pore filter.

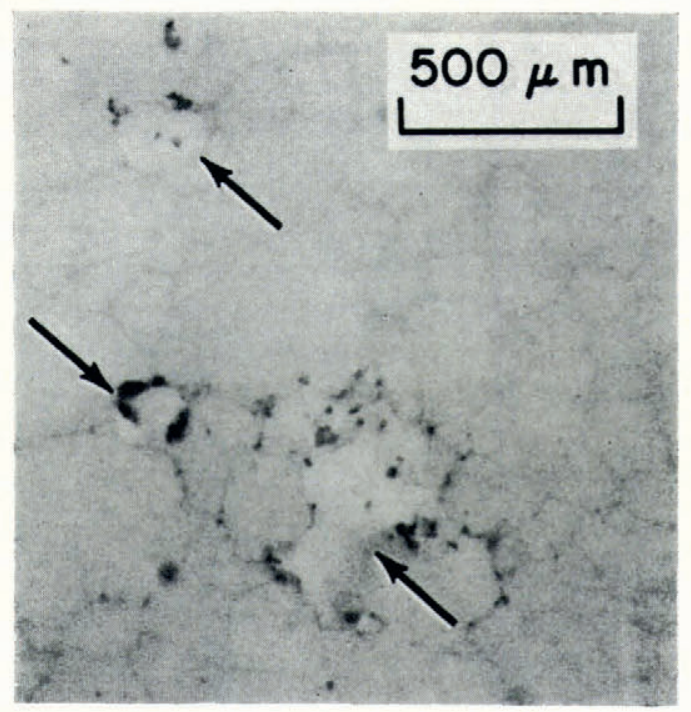

Fig. 4. Chloride reaction patterns of air bubbles (shoun by arrows) in a hailstone (on $0.22 \mu \mathrm{m}$ pore filter). 
Intense spots of solute were always noticed along boundaries of individual air bubbles in any examined hailstone; an example is shown in Figure 4 where the bubbles are contrasting with a faint background of grain boundaries.

Figures 3 and 6 show replicas made an $0.8 \mu \mathrm{m}$ pore-size filters. By using a larger pore-size filter a heavier or darker reaction pattern resulted due to deeper penetration of the ice surface into the pores. In this experiment a more quantitative evaluation could be made of the total chloride content at different zones in the hailstones, but the finer details of the ice-bubble structure and of the crystal grain boundaries were much more prominent in the replicas made on $0.22 \mu \mathrm{m}$ pore size filters as seen in Figures 4,5 , and 7 .

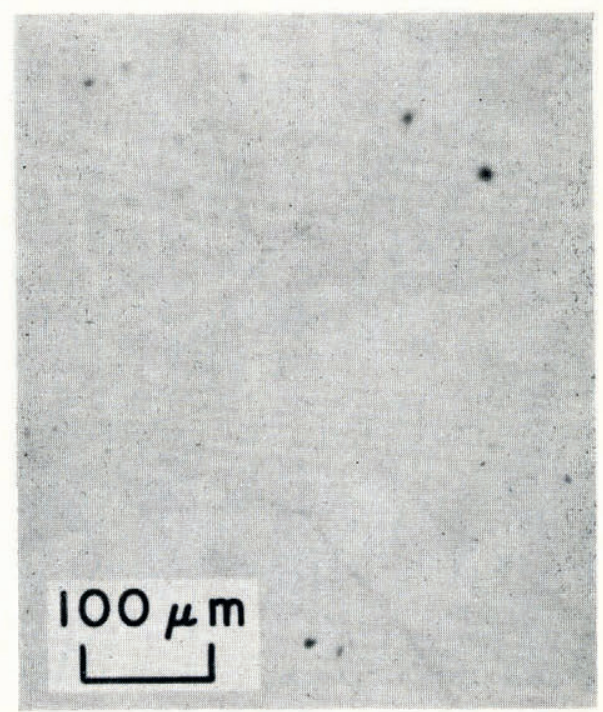

Fig. 5. Faint patterns of chloride reactions along the grain boundaries in a hailstone (on $0.22 \mu \mathrm{m}$ pore filter).

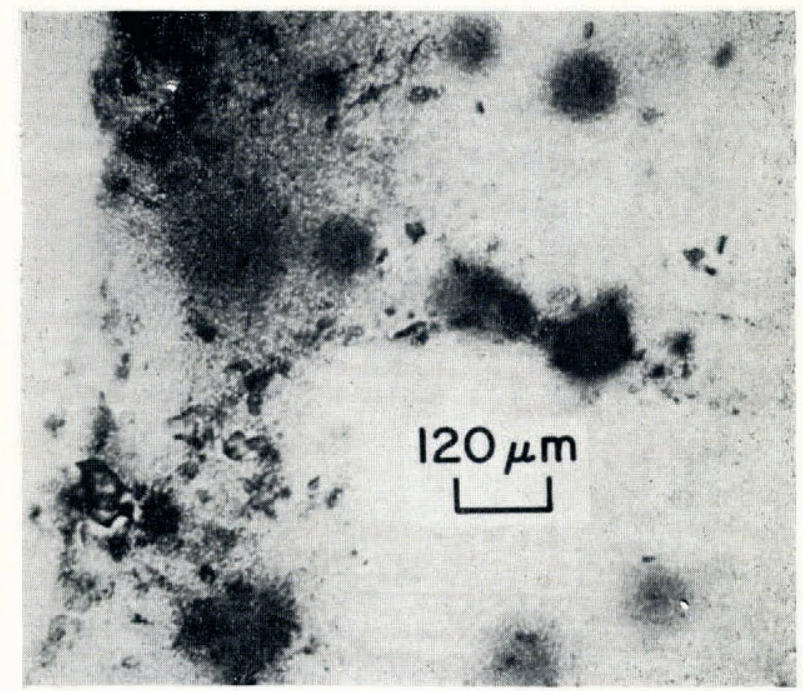

Fig. 6. Chloride reactions from contaminating particles near the periphery of a hailstone (on $0.8 \mu m$ pore filter). 


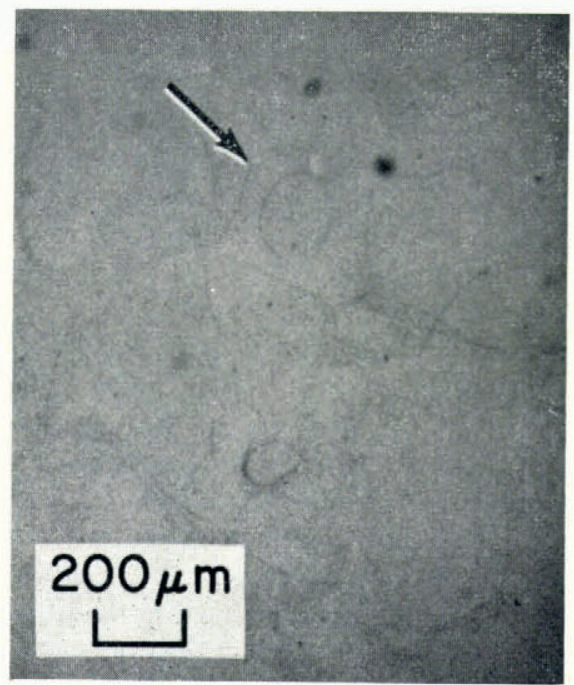

Fig. 7. Chloride reaction pattern showing a loop resembling a dislocation of Frank-Read type (on o.22 4 m pore filter).

Although weak in intensity, solute reaction patterns seem to be observable by this technique along sub-grain boundaries and dislocation lines in accordance with the theory of dislocations in metals. In fact, Cottrell (r953) has demonstrated that the solubility of a solute atom is higher in a dislocation than elsewhere, and the solute atoms will be located preferentially in the expanded region near a dislocation. Each dislocation will collect more solute atoms during solidification when the mobility of solute atoms is high. Therefore, it would be expected that those types of volume sources called Frank-Read sources which can reach maximum dimensions of a few hundred micrometers, could be readily observed by

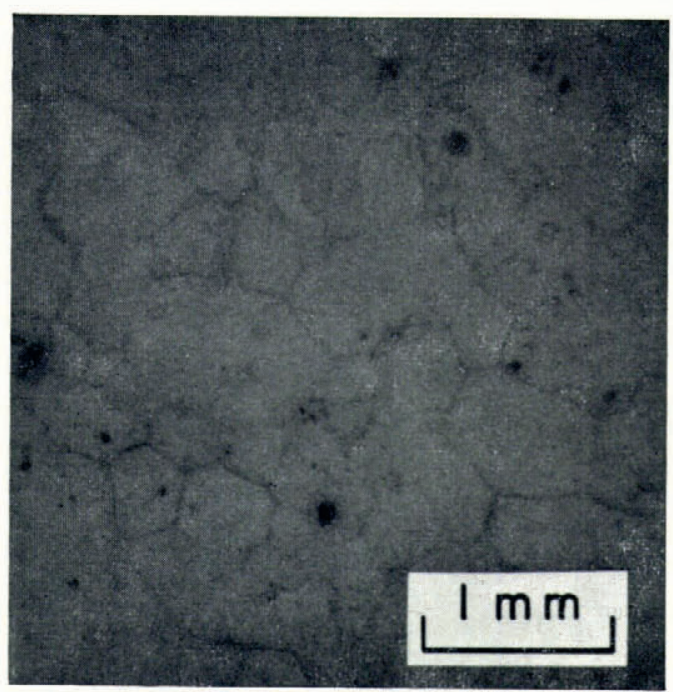

Fig. 8. Chloride reaction patterns showing the undissolved particles, the tiny bubbles, and grain boundaries of different intensities within a hailstone (on $0.22 \mu \mathrm{m}$ pore filter). 
the reaction pattern produced at such dislocation regions. This dislocation shape emerges when a step begins on the surfaces fixed in the ends by a right-handed and a left-handed screw dislocation, and this step being anchored grows only by bulging.

A feature resembling such a dislocation was apparent in the hailstones examined; an example is given in Figure 7 together with grain and subgrain boundary patterns. The size is in accordance with observations of Dash (1956) on dislocation loops in silicon.

A remarkable difference was noticed in the chloride content of embryos from one hailstone to another. Sometimes a very high content was found due to the presence of giant particles; in other embryos the region was almost chloride-free.

It is probable that this technique of observing the chloride distribution within a hailstone could be used to determine the hailstone's internal features. As seen in one small section of a chloride reaction replica (Fig. 8), the grain size and its boundaries, the many tiny bubbles (in this relatively clear ice zone), and the chloride particulates, all can be exactly located within this hailstone. Conclusions seem premature relating the environmental growth conditions of hailstones to the chloride distributions, since the filter technique should also be applied to contaminated ice artificially grown by accretion. Further investigation is needed of the way in which the solute is segregated during freezing of individual droplets in different growth conditions as well as studies of varying ice densities of the resulting dry accretion. It is expected that a distribution of chlorides on the filter in the dry growth will have different patterns from those in the wet or spongy accreted ice. This could give a criterion for distinguishing the different types of growth, which eliminates the effects of migration using the evaporation technique. Moreover, the effect on chloride distribution of the final freezing of liquid water seeping into a low density, porous structure should be investigated by this technique. In fact, the frequent penetrating channels of reactions, the high chloride content of the peripheral layer, and the above-mentioned correlation between pattern intensity and crystal sizes seem to add evidence for a model which implies a final wetting and freezing of a previously formed porous structure.

\section{B. Solute segregation in ice from a low concentration $\mathrm{NaCl}$ solution}

A $\mathrm{NaCl}$ solution $(0.3 \mathrm{~g} / \mathrm{l})$ was radially frozen at $-25^{\circ} \mathrm{C}$ in a plastic cylinder $(4.5 \mathrm{~cm}$ diameter) insulated on top and bottom. Chloride filter replicas were taken on sections normal to the cylinder axis, the plane having been shaved flat by using the microtome. Results are shown in Figure 9 which gives from left to right the chloride distribution from the periphery toward the center. As we observed in hailstones, complete solute segregation exists along grain boundaries. There is evidence of a surface layer of high chloride concentration followed by a region of poor concentration gradually increasing toward the center. Similar behavior was found by Smith and Pounder (1960) through chemical analysis of
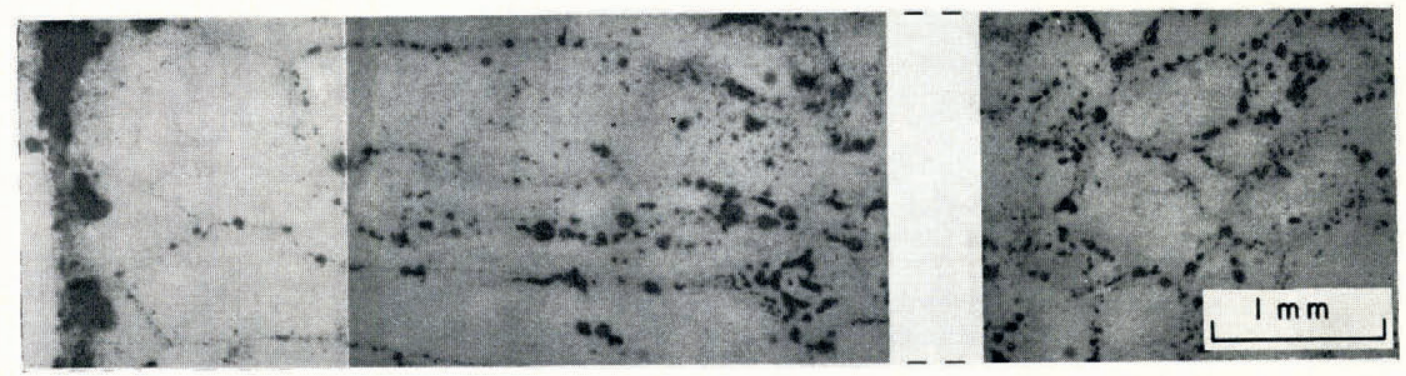

Fig. 9. Reaction patterns obtained from bulk ice frozen from a low concentration $\mathrm{NaCl}$ solution. 
melted slices cut at different distances from the surface. Apparently they were unable to demonstrate the existence of a surface layer of concentrated chlorides and could not correlate the distribution with internal features.

\section{Solute segregation in ice from $\mathrm{NaCl}$ solution of sea-water concentration}

A $30 \mathrm{~g} / \mathrm{l} \mathrm{NaCl}$ solution was radially frozen in the same conditions as the former solution. As mentioned before, with ice at high $\mathrm{NaCl}$ content, a modification was introduced in the technique, since the filter could be wetted and a reaction shown to be taking place at very
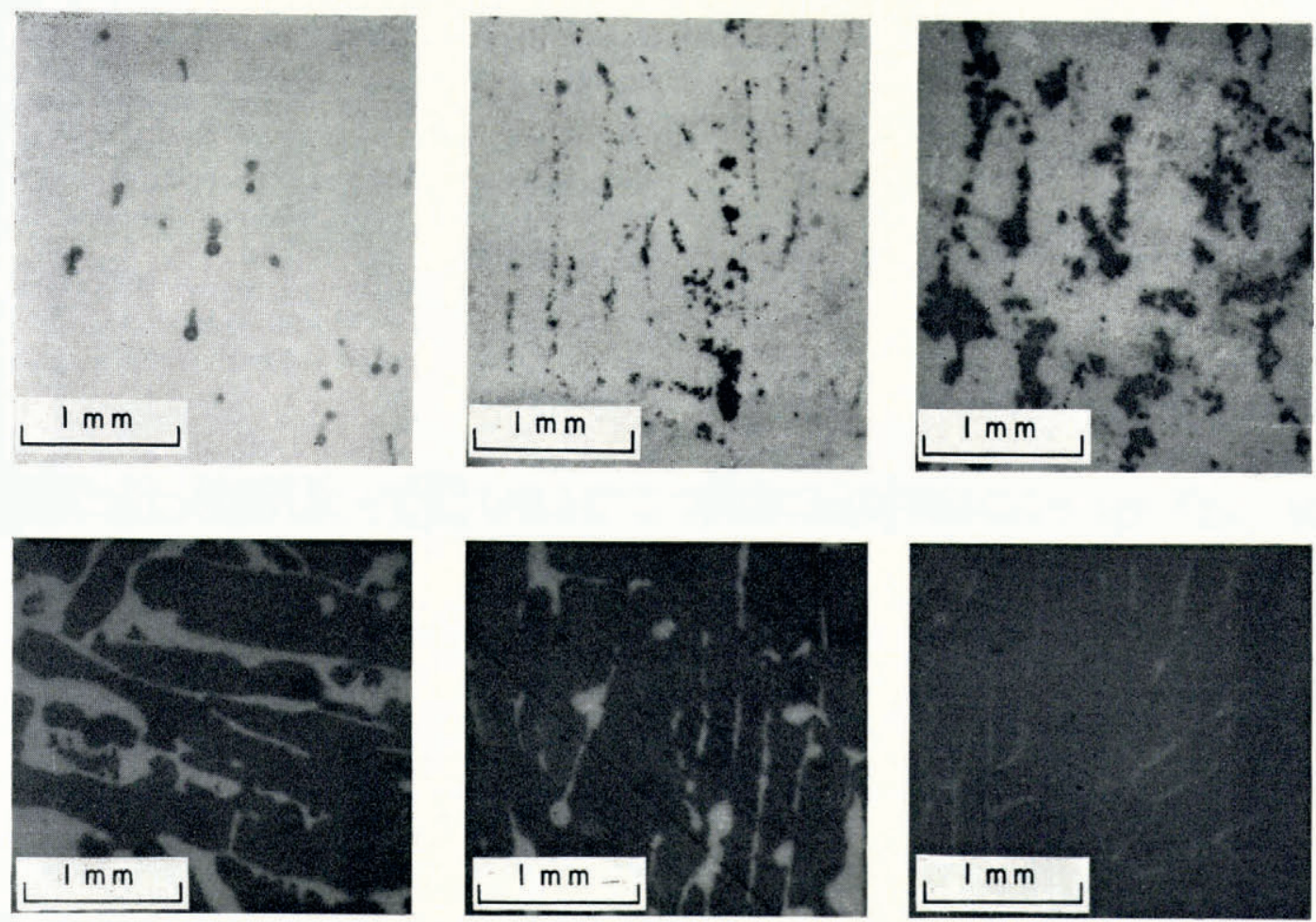

Fig. Io. Reaction patterns obtained from bulk ice frozen from a $30 \mathrm{~g}$ per liter. $\mathrm{VaCl}$ solution. Reaction obtained at various temperatures. From top left to bottom right successive photographs show the results of reactions at $-2 I .2^{\circ} \mathrm{C},-2 \mathrm{C} .5^{\circ} \mathrm{C}$, $-20.0^{\circ} \mathrm{C},-19.5^{\circ} \mathrm{C},-19.0^{\circ} \mathrm{C}$, and $18.0^{\circ} \mathrm{C}$.

low temperatures. The ice surface and the filter were placed on a cold plate whose temperature was finely regulated. In a sequence of pictures from Figures i oa to i of results are shown on filter patterns corresponding to gradually warmer temperatures from $-2 \mathrm{I} .2^{\circ} \mathrm{C}$ (eutectic) to $-18^{\circ} \mathrm{C}$. The pressure exerted on the ice rod was also critical, and was kept constant for all the experiments.

In Figure roa the chlorides are concentrated in brine droplets; they are segregated successively between platelets of relatively pure ice (Fig. Iob). As the temperature increases, they expand until they completely cover the filter (Fig. Iof). 


\section{Conclusions}

The filter technique which we have described allows a precise detection of chlorides in ice without altering their distribution. The simple procedure with its feasible application to natural ice also makes it suitable for field tests on freshly fallen hailstones. An almost complete segregation has been confirmed of chlorides along grain boundaries as well as along the air-ice boundaries of the enclosed air bubbles. Chlorides due to particulate material in hailstones give spots clearly distinguishable from the grain patterns caused by the dissolved ions; particulates are mostly found along the external surface layer, along the penetrating channels between lobes, and sometimes in the embryo region.

A correspondence between crystal sites and chloride content has been found in different layers; it seems questionable whether this relationship should be explained as due to the difference in chloride contents of the cloud, or to various crystallization velocities during the final freezing of a dry-wetted structure. To answer this question, and to infer from the filter replica the environmental growth conditions of the hailstones, tests of this technique should be made on contaminated ice artificially grown by accretion.

The technique, when tried on low concentration $\mathrm{NaCl}$ solutions frozen in the laboratory, shows the existence of a surface layer of high chloride content and gives an evaluation of distribution of chlorides versus the distance from the surface.

With ice from a solution containing sea-water $\mathrm{NaCl}$ content, the technique shows the different brine features in the ice matrix at different temperatures. This technique may also be useful in studying processes largely responsible for the physical properties of sea ice: brine trapping during freezing, and micro- and macro-segregation.

MS. received 28 August 1970

\section{REFERENCES}

Cottrell, A. H. 1953. Dislocations and plastic flow in crystals. Oxford, Clarendon Press.

Dash, W. C. 1956. Copper precipitation on dislocations in silicon. Fournal of Applied Physics, Vol. 27, No. 10, p. I I $93-95$.

Itagaki, K. ${ }^{1967}$. Particle migration on ice surfaces. (In Oura, H., ed. Physics of snow and ice: international conference on low temperature science. . . . I966. . . Proceedings, Vol. I, Pt. I. [Sapporo], Institute of Low Temperature Science, Hokkaido University, p. 233-46.)

Langer, G. Unpublished. Modification of the membrane technique to efficiently detect and study silver iodide ice nuclei. [Paper read at the second National Conference on Weather Modification of the American Meteorological Society, 1970.]

Levi, L., and others. 1964. Thermal etching on ice crystals, by L. Levi, S. M. de De Micheli and L.. Lubart. Physica Status Solidi, Vol. 4, No. I, p. $63-70$.

Mizuno, Y., and Kuroiwa, D. 1970 . Solute segregation in ice observed by autoradiography. Fournal of Glaciology, Vol. 9, No. 55, p. $117-24$.

Prodi, F., and others. r 970 . Distribution of contaminants in ice grown by accretion, [by] F. Prodi, V. Prodi and G. Fiore. Journal of Applied Meteorology, Vol. 9, No. 2, p. 283-88.

Smith, M., and Pounder, E. R. I 960 . Impurity concentration profiles in ice by an anthrone method. Canadian Fournal of Physics, Vol. 38, No. 3, p. 354-68.

Vittori, O. A., and others. 1969. Natural tracer distribution in hailstones, by O. A. Vittori, F. Prodi, G. Morgan and G. Cesari. Fournal of the Atmospheric Sciences, Vol. 26, No. I, p. $14^{3-52 .}$ 